But really there must be some agreement between us and the said eminent men as to what practical science is when the examination paper is composed.

May I give my iilustration? The Cambridge Local Syndicate have introduced Elementary Experimental Science, three papers, into their junior syllabus. The other day I set two of these three papers for 1899 to a number of boys who had had a most careful experimental training in the matter of the syllabus. They made wry faces over it, and were heard to remark afterwards that they did not see what it had to do with the experiments they had been doing. On marking the papers I found that the best boys, really very good and careful experimenters and observers and good draughtsmen, for boys, barely reached forty per cent. of the marks. The same papers were set to a sharp boy of the same age who had done no experiments, but had been through the same subjects, mechanics, hydrostatics, and heat, in the old way, viz., text.bouk and problems. He siored nearly full marks on all the physics questions.

The fact is, that except for the heading, "Experimental Science," there is nothing in two of these papers to indicate that they are set to candidates whose knowledge is based on and drawn from experimental work of their own.

I should like to ask you to print these papers in full, that the eminent men who set them might have a chance of saying something, but on the whole I think your space is too valuable. I will simply quote two questions from the mechanics paper.

"(3) Explain how work is measured, and in what units

"A $50 \mathrm{lb}$. shot is fired from a cannon with a velocity of 1500 feet per second. Compare the work done on the shot with that done by a man weighing I 2 stone who walks up a hil 1500 feet high.

"(4) What is the mechanical advantage of a machine?

"How would you arrange three separate pulleys, each of which weighs I lb., so that the power required to raise a weight of 40 lbs. may be a minimum?

"What arrangement of pulleys is most commorly used in practice? And why?"

Now these are exactly the old Cambridge-" Describe the common pump, \&c., questions?" and the way to answer them is to waste no time on experiments, but read your text-book, get up your formulic and work examples. The second question is of exactly the same type. The other two require a graphical construction, but such as would be readily done by a boy who had used a text-book in which graphic methods were explained.

The first paper is almost equally bad; it is all (chemistry included) text-book science of a very common order. Against the practical paper I have nothing to say.

Now Cambridge men can write excellent elementary text books on these subjects, witness those of Prof. Clazebrook. Can they not produce among them a paper on Elementary Experimental Science, which shall be what it professes to be or is the tradition of the common pump still too strong, and the impress of the Mathematical Tripos too indelible?

$$
\text { A. II, F. }
$$

\section{Literature of Coffee and Tobacco Planting.}

IN the issue of NATLRF of August 9 it is stated, in reviewing a book by a French author, that several books on the same subject, i.e. coffee-its growth, cultivation and preparation for the market-have already been published in English.

Could you kindly inform me of the names of the publishers or authors of any good works in English on coffee and tobacco growing? I have been, so far, quite unable, out here, to find the names of any publishers of works on tobacco or coffee, and as it is a matter of considerable moment to me to gain the best of information on these subjects, I trust you will see your way to help me.

Salisbury, Rhodesia, South Africa.

G. H. JAMES.

[Mr. J. R. Jackson, Keeper of Museums at the Royal Gardens, Kew, to whom we referred our correspondent's inquiry, has kindly sent the following list of books, which may meet the requirements and also be of service to other planters. -Ed. NaTURE.]

Works on Coffee and Tonacco Planting.

"The Coffee Planter of Ceylon," by William Sabonadiere. Published by E. and F. N. Spon, I25, Strand. (1870.)

"Coffee Planting in Southern India and C')lon," by E. C. P.

Ifull. F. and F. N. Spon. (1877.)

No. 1618 , VOL. 63]
Article on coffee in "Spon's Encyclopredia of the Industrial Arts, Manufactures and Commercial Products." E. and F. N. Spon.

"Liberian Coffee in Ceylon." From the Ceylon (Observer. Published at Colombo by A. M. and F. Ferguson, (1878.)

"All About Tobacco." Compiled by A. M. and F. Ferguson, Colombo, Ceylon. Agents, John Haddon and Co., Bouverie Street, Lonion.

Article on tobacco in "Spon's Encyclopredia of the Industrial Arts, Manufactures and Commercial Products." E. and F. N. Spon.

\section{Autotomic Curves.}

IN NATure, October II, Mr. A. B. Basset justly inveighs against the use of the term "non-singular curve" to denote a curve which has no double points. Doubtless, also, the ex. pression "an anautotomic curve" is objectionable.

May I suggest that, in this instance, we may obtain from Latin the help unknown to Greek, and designate curves which have, and curves which have not, double points, by the terms se'secting and non-sesectins respectively?

H. LANGHORNE ORCHARD.

44 Denning Road, Hampstead, ‥ $F^{2}$., October 20.

IN answer to your correspondent, Mr. A. B. Basset, would not the Anglo-Saxon negative prefix "un" combine more euphoniously with "autotomic" than the (rreek "an"? We find analogy for such a combination in the familiar words "un. authorised" and "unauthenticated," where it is used in conjunction with words of Latin origin; so there seems no valid philological objection to its association with a Greek derivative, while the phrase "an unautotomic curve" would certainly sound morc pleasantly to the ear than "an anautotonic" one.

4, Malcolm Road, Penge, S.E., Octoher 25.

ARTHUR S. THORN.

\section{THE PRESENT CONDITION OF THE INIIIGO} INDUSTRY.

F late years attention has often been drawn to German Technical Chemistry, more especially in connection with the advance and growth of the coal-tar colour industry, an industry which received its birth in this country, but which has now taken up its abode on the continent, the loss of the industry to this country being largely due to the conservatism of our manufacturers, and also partly to the want of proper scientific training on the part of the few chemists whom the manufacturers have deigned to employ. ${ }^{1}$

Before 1870 the madder plant was very largely cultivated, in order to obtain from it the important dye-stuff alizarin. I3ut in 1869 a process for obtaining alizarin, by fusing anthraquinone sulphonic acid with caustic soda, was patented simultaneously in this country and in Germany. As a consequence the niadder plant is now hardly cultivated at all. ${ }^{2}$ Now, thirty years later, another and perhaps even more important natural dye-stuff is in jeopardy owing to the advances of German science. The dye-stuff referred to is indigo, which is cultivated in such large quantities in our Indian Empire. If, then, the natural indigo is to be driven out of the market by the artificial substance, prepared from coal-tar products, it cannot fail to exert a great temporary, if not permanent, influence upon the wealth of India. Perhaps, then, a

1 In the hand-book for the International Exhibition of 1862 (vol. i. p. I 20), the following sentences occur: "It is impossible to overrate the impirtance of the coal-tar dyes to this cuuntry. From having the sources of the raw material in unlimited quantities under our very feet, we are enabled to compete most favourably with continental nations in this respect, and we shall soon become the great colour exporting country, instead of having, as hitherto, to depend on Holland and other countries for our supply of dye. stuffs."

$2 \mathrm{M}$ adder root contains about I per cent. of alizarin, and in $1859^{-1868}$ he bedder rof the best qualities of Turkey roots retched $50 s$. per cur , this would make the price of alizarin about $45 s$. per llo. When art produ $\mathrm{ed}$, the dry product fetched abuut 45 s. to 50 s. per lb. A 20 per cent.
paste of alizarin is now sold for $7 d$. per $1 \mathrm{~b}$. 